DOI: https://doi.org/10.24867/07GI07Krstic

\title{
ANALIZA PROCESA OSIGURANJA OD POSLEDICA NESREĆNOG SLUČAJA (NEZGODE)
}

\section{ANALYSIS OF THE INSURANCE PROCESS OF ACCIDENT INSURANCE}

\author{
Jelena Krstić, Fakultet tehničkih nauka, Novi Sad
}

\section{Oblast -INŽENJERSKI MENADŽMENT}

Kratak sadržaj - U radu je opisan proces zaključenja ugovora o osiguranju od posledica nesrećnog slučajanezgode, tok dokumentacije, realizacija osiguranih slučajeva i proces prijave i likvidacije štete.

Ključne reči: Osiguranje, nesrećni slučaj, procena, šteta

Abstract - In this paper two proceses are analysed, first is the process of contracting accident insurance and second is the proces of damage liquidation.

Keywords: Insurance, accident, assessment, loss

\section{UVOD}

Prvi deo ovog rada se bavi procesom osiguranja lica od posledice nesrećnog slučaja (prikazano na slici br.1: Dijagram toka procesa osiguranja). Definiše pojmove vezane za osiguranje, rizike koji se mogu osigurati i objašnjava potrebne postupke.

Prodavac osiguranja (agent) pre stupanja u kontakt sa potencijalnim osiguranikom vrši proveru delatnosti poslovanja da bi na pravi način mogao da odredi kojem razredu opasnosti pripada i kako bi napravio ponudu koja odgovara. Nakon toga sastavlja ponudu po tarifi koja odgovara definisanoj delatnosti izraženu po radniku na godišnjem i mesečnom nivou. Prilikom kontakta sa potencijalnim osiguranikom prodavac osiguranja predstavlja napravljenu ponudu uz napomenu da je korekcija moguća ukoliko ima potrebe za istom.

Prodavac osiguranja prilazi izradi polise i prateće dokumentacije i dostavlja dokumentaciju tariferu koji vrši proveru tarife osiguranja koja je primenjena i da li je prateća dokumentacija pripremljena u skladu sa pravilnikom. Zatim, osiguranik parafira dokumentaciju svojim potpisom i pečatom firme, organizacije, dobija svoje primerke a prodavac vraća svoje primerke tariferu koji vrši još jednu proveru. Jedan primerak dokumentacije ostaje prodavcu osiguranju, a drugi ide u zvaničnu arhivu firme.

Drugi deo rada se odnosi na ispoljenje osiguranog rizika, odnosno proces prijave, likvidacije i naknade štete iz osiguranja (prikazano na slici br. 2: Dijagram toka procene i likvidacije štete).
Prijemni radnik koji radi na prijavi štete iz osiguranja prilikom dolaska osiguranika potražuje polisu osiguranja kako bi se uverio da je osiguranik osiguran $u$ toj osiguravajućoj kući i da je ispoljeni rizik pokriven važećom polisom osiguranja.

Nakon što utvrdi da je ispoljeni rizik pokriven polisom osiguranja izdaje obrazac prijave štete koji osiguranik popunjava i odnosi kod ugovarača na overu. Svojom overom i prilogom spiska osiguravač potvrđuje da je osiguranik osiguran po zadatoj polisi.

Zajedno sa prijavom osiguranik dostavlja i medicinsku dokumentaciju, ličnu kartu (ukoliko je u pitanju maloletno lice dostavlja se lična karta roditelja/staratelja/hranitelja), kartica tekućeg računa (ukoliko je u pitanju maloletno lice dostavlja se kartica tekućeg roditelja/staratelja/hranitelja), ili ako osiguranik ne poseduje tekući račun u banci zaokružuje opciju isplate preko poštanske uputnice.

Kada prijemni radnik utvrdi da je dokumentacija kompletna prosleđuje predmet likvidatoru štete koji prvo dostavlja dokumentaciju lekaru-cenzoru da utvrdi procenat invalidnosti i visinu povrede.

Nakon utvrđenog procenta štete likvidator određuje visinu naknade koju određuju osigurana suma i procenat oštećenje - invaliditeta. Predmet zatim ide na kontrolu kod kontrolora koji utvrđuje da li je proces likvidacije određen pravilno

Kontrolor kada utvrdi da su svi poslovi pravilno odrađeni vraća predmet likvidatoru koji štampa odluku o likvidaciji u dva primerka, jedan primerak šalje osiguraniku koji prilikom prispeća iste ima rok od 15 dana na žalbu, a drugi sa primljenom povratnicom odlaže u predmet štete.

Po isteku 15-og dana od dana prijema odluke o likvidaciji likvidator štete predaje predmet računovodstvu na isplatu, a ako u međuvremenu pristigne pismena ili usmena žalba osiguranika ona se upućuje komisiji za prigovore.

Dalje u radu su prikazani procesi osiguranja, procene i likvidacije štete. Na slici br. 1 je prikazan dijagram toka procesa osiguranja od momenta stupanja u kontakt sa potencijalnim osiguranikom do same izrade polise i arhiviranje dokumenata.

Prilikom prijave i rešavanja odštetnog zahteva potrebno je pratiti korake prikazane na slici br. 2: Dijagram toka procesa likvidacije štete.

\footnotetext{
NAPOMENA:

Ovaj rad proistekao je iz master rada čiji mentor je bila dr Ljiljana Popović
} 


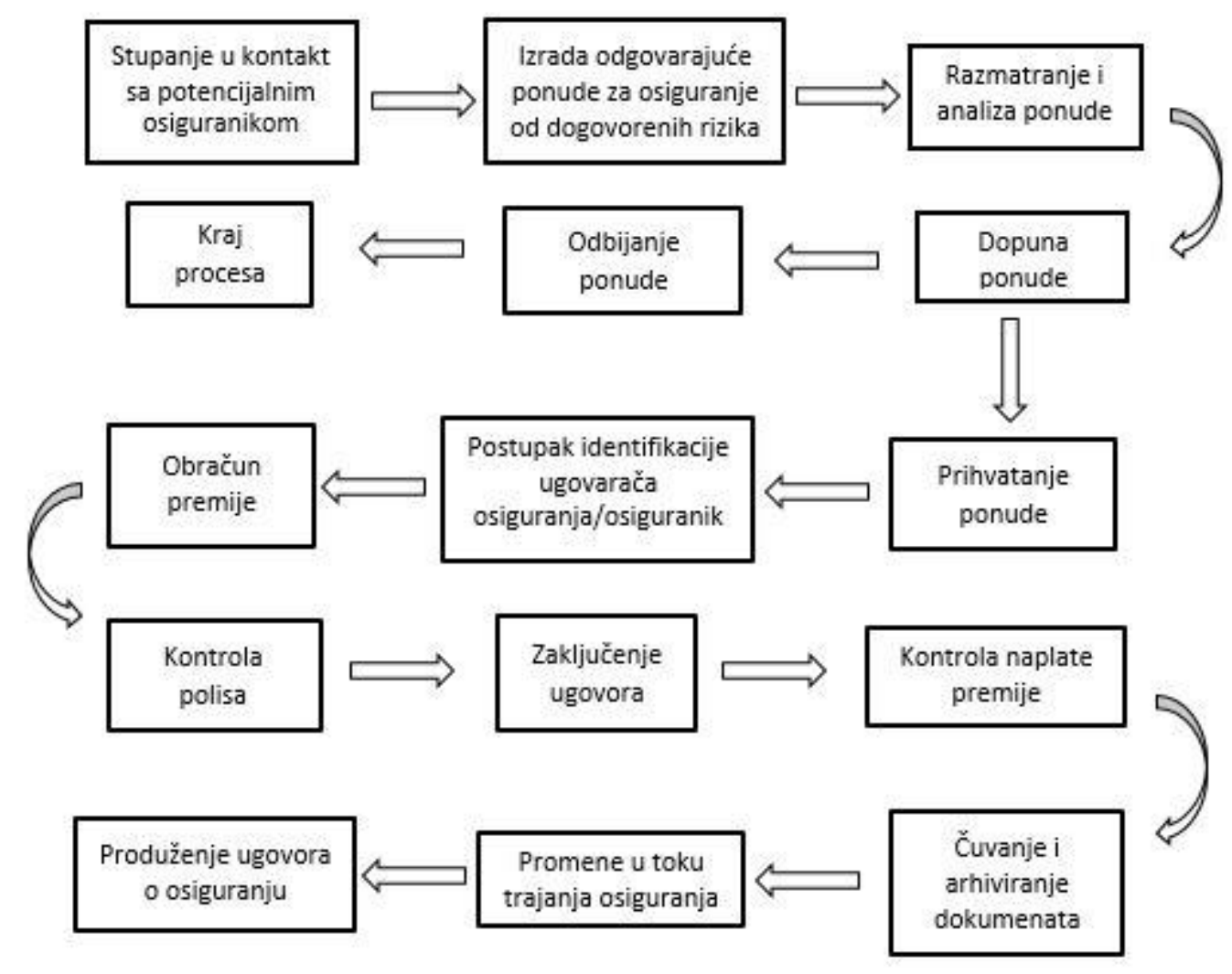

Slika 1. Dijagram toka procesa ugovaranja osiguranja

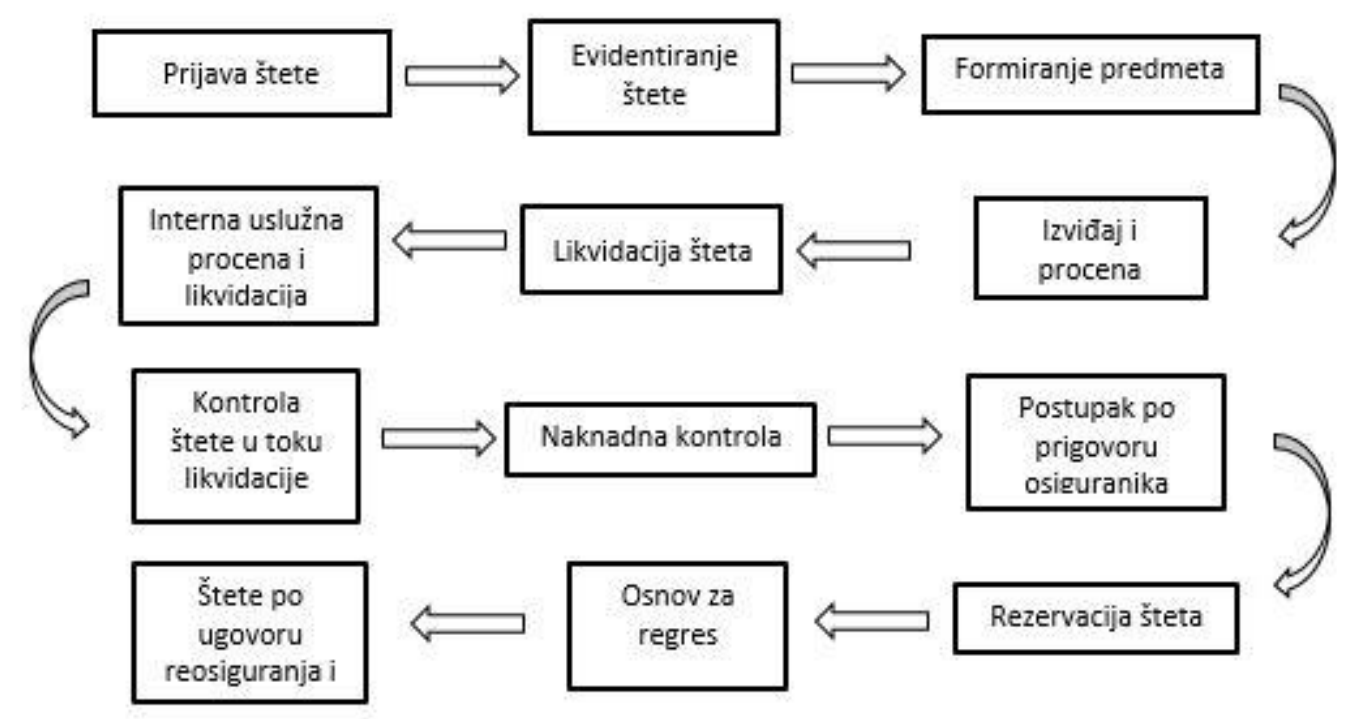

Slika 2..Dijagram toka procesa likvidacije štete

\section{POJAM OSIGURANJA}

Osiguranje predstavlja specifičnu vrstu zaštite, obezbeđenja, poverenja u nešto, sigurnosti. Ekonomski je institut nadoknade šteta nastalih u privredi ili kod ljudi, usled dejstva prirodnih rušilačkih sila, nesrećnih slučajeva i ljudskih grešaka što osiguranje čini oblasti od posebnog društvenog i ekonomskog interesa [1]. Osiguranje je multidisciplinarna nauka jer se javlja u tri vida [1]: 
1. Ekonomski vid koji se izražava u cilju koji se postiže u osiguranju- to su funkcije osiguranja

2. Tehnički vid je onaj deo koji uređuje funkcionisanje osiguranja kao specifičnog mehanizma za izjednačavanje rizika

3. Pravni vid koji predstavlja uređivanje veoma brojnih pravnih odnosa koji nužno nastaju u osiguranju udruživanjem sredstava za obeštećenje svih osiguranika koje zadesi šteta.

Osnovni elementi osiguranja su:

1. predmet osiguranja,

2. osigurana opasnost (rizik),

3. premija osiguranja,

4. osigurani slučaj i

5. naknada iz osiguranja

Ostvarenje osiguranog slučaja u osiguranju nastaje delovanjem rizika na osiguranu stvar ili lice [2]. Štete u osiguranju su mnogobrojne i prema generalnoj podeli se mogu podeliti na:

- materijalne štete $\mathrm{i}$

- nematerijalne (moralne) štete.

Moralne štete se mogu definisati preko pojma moralne imovine, pod čim treba podrazumevati skup ličnih dobara koja pripadaju jednom licu: čast, ugled, telesni integritet [3].

\section{POJAM NESREĆNOG SLUČAJA}

Pojam nesrećnog slučaja definiše se kao svaki iznenadni i od volje osiguranika nezavisni događaj, koji delujući uglavnom spolja i naglo na telo osiguranika, ima za posledicu:

- njegovu smrt,

- potpuni ili delimični invaliditet- smatra se trajni (doživotni) gubitak opšte radne sposobnosti osiguranika, koja može biti potpuna(100\%) ili delimični (od 1 do 99\%),

- prolaznu nesposobnost za rad- nesposobnost za vršenje redovnog zanimanja,

- narušenje zdravlja koje zahteva lekarsku pomoćpredstavlja samo one povrede i oboljenja koja su posledica nesrećnog slučaja a radi čijeg lečenja je potrebna lekarska pomoć. [2]

\section{OBRAČUN PREMIJE I ŠTETE IZ OSIGURANJA OD POSLEDICA NESREĆNOG SLUČAJA - NEZGODE}

U daljem tekstu dat je primer sklapanja ugovora osiguranja od posledica nesrećnog slučaja (nezgode), kao $\mathrm{i}$ ispoljenje osiguranog rizika.

Trenera rukometnog tima zanima na koji način može da obezbedi svoje igrače dok su na treninzima u sportskoj hali, kao i na utakmicama.

Rukometni klub se ne takmiči u Prvoj ligi i ne tretiraju se kao profesionalci, već kao amateri te se mogu osigurati kao članovi sportske organizacije, pod tarifnom grupom sportista- amatera.

Klijent je tražio ponudu od osiguravača koja sadrži sledeće elemente:
- Smrt usled nesrećnog slučaja (nezgode) na sumu od 500.000 dinara

- Trajni invaliditet usled nesrećnog slučaja (nezgode) na sumu od 1.000.000 dinara

- Troškovi lečenja u iznosu od 20.000 dinara

Tarifa Osiguranja od posledica nesrećnog slučaja (nezgode) sadrži sledeće tarifne grupe:

- Tarifna grupa 1- osiguranje lica od posledica nesrećnog slučaja pri obavljanju i van obavljanja redovnog zanimanja

- Tarifna grupa 2- osiguranje lica od posledica nesrećnog slučaja u motornim vozilima i pri obavljanju posebnih delatnosti

- Tarifna grupa 3- osiguranje dece, učenika i studenata od posledica nesrećnog slučaja

- Tarifna grupa 4- posebna osiguranja omladine od posledica nesrećnog slučaja

- Tarifna grupa 5- osiguranje gostiju, posetilaca i turista od posledica nesrećnog slučaja i osiguranja odgovornosti ugovarača osiguranja

- Tarifna grupa 6- osiguranje potrošača, pretplatnika i korisnika drugih javnih usluga od posledica nesrećnog slučaja

- Tarifna grupa 7- posebna osiguranja lica od posledica nesrećnog slučaja

- Tarifna grupa 8- obavezno osiguranje putnika u javnom prevozu od posledica nesrećnog slučaja.

Za konkretan slučaj, premija se obračunava prema Tarifnoj grupi 1 - osiguranje lica od posledica nesrećnog slučaja pri obavljanju i van obavljanja redovnog zanimanja. U okviru Tarifne grupe 1 nalazi se dopunsko osiguranje sportskih rizika. U okviru ove tarifne grupe definisani su sledećei razredi opasnosti koji utiču na premijsku stopu osiguranja:

- I razred opasnosti - gimnastika, atletika, badmington, golf, kuglanje, mačevanje, odbojka, plivanje, ribarstvo, sankanje, šah, tenis,

- II razred opasnosti - biciklizam, jahanje, lovački sport, skijanje, vaterpolo, skokovi u vodu,

- III razred opasnosti - rukomet, fudbal, ragbi, bejzbol, američki fudbal, motociklizam, automobilizam, planinarenje, rvanje, džudo, ronioci, alpinizam.

Sportisti - amateri rukometa spadaju u III razred opasnosti.

Premija osiguranja se dalje izračunava na sledeći način:

$$
P=O . S . \times P . S \text {. }
$$

Pri čemu $\mathrm{P}$ predstavlja premiju osiguranja, O.S. predstavlja osiguranu sumu, a P.S. predstavlja premijsku stopu.

Premijska topa za rizik „Smrt usled nesrećnog slučaja (nezgode)“ u gore pomenutoj tarifnoj grupi iznosi 1,40\%o. Shodno pomenutom, premija osiguranja za ovaj rizik iznosiće:

$$
500000 \times 1,40 \%=700 r s d
$$


Premijska topa za rizik „Trajni invaliditet usled nesrećnog slučaja (nezgode)“ iznosi 1,40\%o. Premija osiguranja za ovaj rizik iznosiće:

$$
1000000 \times 1,40 \%=1400 \mathrm{rsd}
$$

Premijska topa za rizik „Troškovi lečenja“ iznosi 24\%o. Premija osiguranja za ovaj rizik iznosiće:

$$
20000 \times 24 \%=480 r s d
$$

$\mathrm{Na}$ osnovu prethodno proračunatog, ukupna premija po članu rukometnog kluba na odišnjem nivou iznosiće 2.580 dinara. Rukometni klub zajedno sa trenerom i upravnim odborom broji 50 članova, što znači da premija osiguranja na godišnjem nivou iznosi 129.000 dinara.

Nakon pristajanja na datu ponudu klub je u obavezi da priloži spisak svih članova koji će sadržati ime i prezime člana, matični broj i adresu. Sva dokumentacija se overava sa potpisom predsednika kluba ili ovlašćenim zastupnikom kluba i pečatom rukometnog kluba.

Kako je u pitanju sportska organizacija plaćanje se vrši preko fakture, sa tekućeg računa kluba. Dogovoreno je plaćanje od jednom unapred i dat je rok od sedam dana od potpisa polise da se ista plati. Osiguranje počinje 01.08. budući da tada kreću pripreme za novu sezonu koja kreće od 01.10.

Nakon određenog vremena, jedna od članica kluba se povredila 31.12. na zabavi povodom proslave dočeka Nove godine i zadobila je prelom leve ruke u laktu.

Nakon završenog lečenja i terapije u banji klub je podneo prijavu štete. Prilikom preuzimanja predmeta likvidator štete je uočio da su ugovoreni rizici koji se ispolje za vreme treninga i utakmica, ali ne $i$ van njih $i$ osiguravajuća kuća nema osnova za isplatu štete.

Kontrolor štete po pregledu predmeta daje svoju saglasnot na donetu odluku likvidatora. Na odluku o likvidaciji štete se obrazlaže da je šteta odbijena po osnovu ugovorenih rizika i uslova za osiguranje.

Osiguranik je prihvatio obrazloženje, nije uložio prigovor i šteta se odlaže u arhivu.

\section{ZAKLJUČAK}

Osiguranje od posledice nesrećnog slučaja za osiguranika ne predstavlja sticanje profita ili način zarade, već sigurnost u slučaju ostvarenja nekog rizika.

Ono za osiguravača predstavlja novčanu zaradu jer je to za njega poslovna delatnost. Često osiguranici ne shvataju potrebu za osiguranjem jer se vode mišlju da određeni rizik ne predstavlja pretnju po njih.

Uzimajući u obzir visinu premije za osiguranje lica od posledica nesrećnog slučaja i visinu osigurane sume, većina bi se složila da je to mala cena koju treba platiti u odnosu na sigurnost koju ona donosi.
Sve vrste osiguranja su nastale iz potrebe sigurnosti i uverenja ljudima da ako im se nešto desi imaju pomoć, neku vrstu bezbednosti. Čovek je rano uvideo da sam ne može da se nosi sa nedaćama koje su stavljene pred njega i drugih pa je odlučio da je uvek bolje da se pomogne drugima, jer će kad njemu zatreba ti drugi pomoći i vratiti.

Posebnu pažnju treba obratiti na same uslove osiguranja prilikom sklapanja polise jer nisu svi rizici svakom polisom obuhvaćeni. Kao i na proceduru koju je potrebno izvršiti prilikom same prijave nesrećnog slučaja.

Veoma je bitna dobra komunikacija između osiguravača i osiguranika jer se mogu izbeći nepotrebni konflikti, suvišna dokumentacija $i$ uzalodno trošenje vremena $i$ jedne i druge strane. Treba obratiti pažnju i na određene rokove koji su predviđeni uslovima i poštovati ih.

Za razliku od osiguranja imovine, osiguranje od posledice nesrećnog slučaja (nezgode) je podložnije prevarama u osiguranju budući da osiguravač nema drugi uvid u povrede osiguranika osim lekarske dokumentacije koja vrlo lako može da se falsifikuje, dok kod osiguranja imovine prilikom procene procenitelj vidi oštećenje na objektu i može da proceni da li je šteta nastala ispoljavanjem osiguranog rizika ili ne.

Na minimalizaciju moralnog hazarda se može uticati kod nekih vrsta osiguranja. Kod imovinskih osiguranja pre stupanja u osiguranje neophodno je dobro proveriti informacije o oblasti u kojoj se objekat osigurava (da li je i koliko često bilo plavno, kada su i u kojoj meri bili zemljotresi...) umesto verovanja osiguraniku na reč.

Kod osiguranja lica je to teže učiniti. Može se utvrditi sa proverom lekarske dokumentacije, tj. zdravstvenog kartona kako bi se imao uvid u prethodne povrede, lečenja i sl...

Pre stupanja u osiguranje neophodno je više pažnje posvetiti samom osiguraniku kako bi se dobro utvrdili njegovi motivi za osiguranje. Na taj način ne samo da se smanjuje opasnost od moguće prevare u osiguranju već se pospešuje utvrđivanje parametara za osiguranje.

\section{LITERATURA}

[1] Kuzmanović B., Marović B., Njegomir V. :"Osnovi osiguranja i reosiguranja“, Beograd, 2009.

[2] Mrkšić D., Ćosić Đ: „Upravljanje rizikom i osiguranje“, FTN, Novi Sad, 2015.

[3] Avdalović V. „Principi osiguranja“, FTN, Novi Sad, 2007.

\section{Kratka biografija}

Jelena Krstić je rođena u Somboru, 1989. godine. Završila je gimnaziju „Veljko Petrovićc" u Somboru i osnovne studije na Fakultetu tehničkih nauka, Novi Sad, iz oblasti Inženjerski menadžment - upravljanje rizikom i menadžment u osiguranju. 